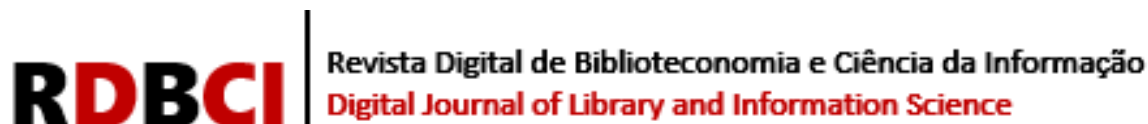

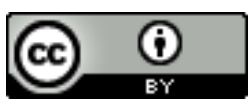

\section{Pessoa com deficiência visual e a acessibilidade à informação para mobilidade indoor}

\author{
Cláudio Gonçalves Bernardo ${ }^{1}$ (D) https://orcid.org/0000-0003-1096-7701 \\ Ivette Kufure Muñoz ${ }^{2}$ iDttps://orcid.org/0000-0002-5758-8226 \\ Tiago Barros Pontes e Silva ${ }^{3}$ iD https://orcid.org/0000-0003-2149-5973 \\ ${ }^{1}$ Universidade de Brasília, Brasília, DF, Brasil / e-mail: claudiogbgb@gmail.com \\ ${ }^{2}$ Universidade de Brasília, Brasília, DF, Brasil / e-mail: ivettekead@gmail.com \\ ${ }^{3}$ Universidade de Brasília, Brasília, DF, Brasil / e-mail: tiago3barros@gmail.com
}

\section{RESUMO}

Introdução: A lei de acessibilidade 10.098 de 2000 estabelece normas e critérios para promover acessibilidade às pessoas com deficiência. Dados do censo realizado pelo IBGE em 2013 informam que do total de 146,3 milhões de pessoas acima de 18 anos, aproximadamente 5,27 milhões são pessoas com deficiência visual (PDV), o equivalente a 3,6\%. Método: Considerando que a informação quando é proporcionada de maneira correta leva melhores condições de mobilidade à PDV, este artigo apresenta a proposta de desenvolvimento de artefato eletrônico que lhe proporcione informação na sua mobilidade em qualquer espaço físico interno, posto que disponibiliza informações sobre distância, profundidade e lateralidade do ambiente, sendo categorizado como um mapa auditivo. Resultados: A partir da perspectiva da Ciência da Informação, abordando conceitos de estudo de usuários, acessibilidade e tecnologia assistiva a proposta trata dos desafios de acesso à informação e também de desafios ao acesso físico. O artefato foi desenvolvido utilizando o sistema Dosvox que é amplamente utilizado por PDV. A Biblioteca Central (BCE) da Universidade de Brasília (UnB) foi o espaço físico escolhido como o local contemplado para o desenho do artefato, por já possuir diversos recursos de acessibilidade à informação para a PDV. Conclusão: O objetivo de proporcionar acessibilidade à informação por meio do artefato desenvolvido foi atingido porque orienta a PDV em sua mobilidade indoor.

\section{PALAVRAS-CHAVE}

Acesso à informação. Usuários da informação. Apoio à pessoa com deficiência. Tecnologia da informação.

\section{People with visual disabilities and information accessibility for indoor mobility}

\begin{abstract}
Introdution: Brazilian accessibility law 10,098 of 2000 establishes norms and criteria to promote accessibility for persons with disabilities. IBGE data from 2013 report that in Brazil out of a total of 146.3 million people over the age of 18, approximately 5.27 million are visually impaired people, equivalent to $3.6 \%$. Method: Considering when information is correctly provided, it brings better mobility conditions to visually impaired, this article presents a development proposal of an electronic artifact that provides information on its mobility in any internal physical space, since it provides information on distance, depth and laterality of the environment, being categorized
\end{abstract}




\section{RDBCI}

as an auditory map. Results: From Information Science perspective, addressing concepts of user study, accessibility and assistive technology, the proposal addresses the challenges of accessing information and also challenges to physical access. The artifact was developed using Dosvox system which is widely used by visually impaired. The University of Brasília Central Library was the physical space chosen as the location contemplated for designing the artifact, as it already has several accessibility resources for information to visually impaired. Conclusion: The objective of providing information accessibility through the developed artifact was achieved because it guides visually impaired people in their indoor mobility.

\section{KEYWORDS}

Access to Information. Information users. Disabilities. Information technology.

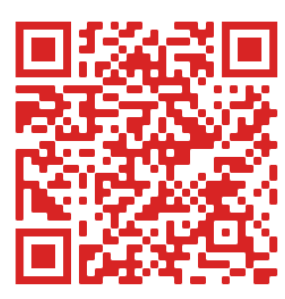

JITA: CB. Users studies 


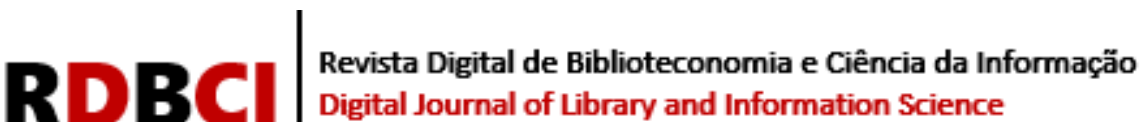

\section{INTRODUÇÃO}

Segundo a Coordenação geral de saúde da pessoa com deficiência do Departamento de ações programáticas estratégicas da Secretaria de atenção à saúde do Ministério da Saúde (CGSPCD/DAPES/SAS/MS) a Convenção internacional sobre os direitos da pessoa com deficiência (ONU, 2016) trouxe novos conceitos de pessoa com deficiência. No Brasil a lei ${ }^{\circ}$ 13.146 (Brasil, 2015) instituiu o Estatuto da pessoa com deficiência, que ampliou o conceito considerando pessoa com deficiência aquela que tem impedimento de natureza física, mental, intelectual ou sensorial, de longo prazo, que pode dificultar a sua convivência perante as barreiras ambientais. É possível dizer que uma pessoa tem deficiência a partir da avaliação psicossocial e assim permite criar instrumentos para um novo tipo de avaliação da pessoa com deficiência, com o objetivo de melhorar a sua inclusão no cadastro nacional de inclusão (BRASIL, 2017).

De acordo com o último Censo demográfico realizado pelo Instituto Brasileiro de Geografia e Estatística (IBGE) em 2010, do total de 190.732 .694 pessoas da população brasileira a deficiência visual atinge 6.585.308, que é o equivalente a 3,5\%. Desse percentual $528.624(8 \%)$ possuem cegueira total e 6.056 .654 possuem baixa visão ou visão subnormal, com grande e permanente dificuldade de enxergar (BRASIL, 2010).

A Comissão de Defesa dos Direitos das Pessoas com Deficiência da Câmara dos Deputados (BRASIL, 2019) está discutindo desde o mês de abril de 2019 o mapeamento das pessoas com deficiência no Brasil, a ser realizado no censo demográfico previsto para ser executado em 2020. Com o anúncio da Organização Mundial de Saúde (OMS) de pandemia provocada pelo novo coronavírus (VEJA SAÚDE, 2020) a realização do censo demográfico foi adiada para 2021 (AGÊNCIA IBGE NOTÍCIAS, 2020). A comissão pretende discutir qual metodologia será adotada na definição de pessoa com deficiência, pois essa definição irá impactar diretamente atores governamentais e não governamentais envolvidos com a causa da pessoa com deficiência.

Sobre as questões do ser humano em suas relações com a tecnologia e sob o ponto de vista da Ciência da Informação (CI) o estudo de Saracevic (1996) questiona em que bases devem ser colocados os problemas, na base humana ou tecnológica? Seguindo sua orientação devemos analisar se a tecnologia constitui, por si mesma, um problema ou uma solução?

Malheiros (2019) apresenta um estudo de usuários com deficiência visual da Biblioteca Digital e Sonora (BDS) da Universidade de Brasília (UnB) e conclui que a informação em meio digital é fundamental para esses usuários e é a mais utilizada; os usuários com deficiência visual acessam todo tipo de informação no computador, mas buscam principalmente informações didáticas e profissionais, onde têm suas necessidades de informação satisfeitas em sua maior parte.

Pimentel (2011) faz um estudo sobre inclusão digital de usuários com deficiência visual e identifica e analisa políticas que orientam programas de acessibilidade nos ambientes que oferecem serviços de informação do Distrito Federal. Esta pesquisa se identifica com os programas e políticas públicas de inclusão digital tecnológica, suas interfaces com o mundo globalizado em torno do papel da informação e do conhecimento nos dias atuais. Sua conclusão é que há necessidade de estabelecer políticas públicas para fortalecer os mecanismos de acesso de informação digital para pessoas com deficiência visual (PDV) e promover a inclusão social e digital como forma de diminuir as desigualdades e barreiras existentes. Também Connors et al. (2013) defendem que para esse público a prática em ambientes virtuais antes da viagem física pode ser benéfica para planejar rotas e evitar dificuldades associadas à tentativa de acessar informações em um ambiente desconhecido. 


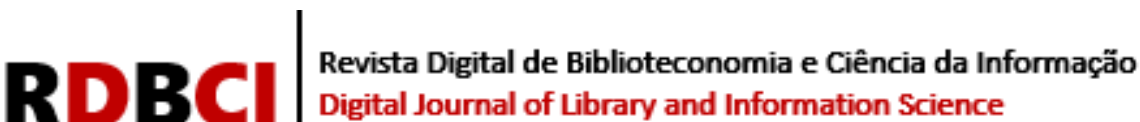

Quanto à questão de estudos de usuários que se envolvam com automação, Baptista e Cunha (2007) esclarecem que estes estudos surgiram na década de 1980 e desde aquela época, completando quase quatro décadas, vem sendo objeto de estudo. Os artefatos eletrônicos precisam ser desenvolvidos para que PDV possam usá-los como Tecnologia Assistiva (TA), à luz do que foi proposto com o simulador de ambiente baseado em áudio apresentado por Connors et al. (2013). Este foi projetado para melhorar as habilidades de navegação do mundo real da PDV pois fornece informações espaciais sobre o layout de um ambiente. Nele o usuário desenvolve um mapa cognitivo espacial preciso de um espaço para desempenhar tarefa de navegação interna, ajudando-o a reduzir a insegurança com a navegação independente antes de conhecer fisicamente um ambiente.

Santos et al. (2018) apresentam evidências das dificuldades apresentadas para desenvolver TA e afirmam que de maneira geral, embora o investimento em pesquisas relacionadas esteja aumentando, a produção tecnológica nacional ainda é limitada.

O número escasso da produção de inovação no Brasil indica a necessidade de estímulos e iniciativas para o aumento da produção e desenvolvimento de TA voltadas para todos tipos de pessoas, pois tais recursos tornam possível a realização de atividades diárias como caminhar em qualquer espaço físico, praticar exercícios, ler um livro e proporcionam inclusão social e qualidade de vida para os usuários.

De acordo com Sá, Campos e Silva (2007) os laboratórios de informática, os tele centros e os programas de inclusão digital deviam contar com meios informáticos acessíveis para pessoas cegas e com baixa visão, porque o uso de computadores e de outros recursos tecnológicos são tão fundamentais para elas quanto os olhos são para quem enxerga, e as expectativas e os investimentos dos educadores deviam ser os mesmos em relação a todos os educandos. Os alunos cegos e com baixa visão têm as mesmas potencialidades que os outros, pois a deficiência visual não limita a capacidade de aprender. As estratégias de aprendizagem, os procedimentos, os meios de acesso ao conhecimento e à informação, bem como instrumentos de avaliação, devem ser adequados às condições visuais destes educandos.

Segundo Sá, Campos e Silva (2007) os meios informáticos ampliam as possibilidades de comunicação e de autonomia pessoal, minimizam ou compensam as restrições decorrentes da falta da visão. Sem essas ferramentas, o desempenho intelectual e profissional da PDV estaria seriamente comprometido e circunscrito a um contexto de limitações e impossibilidades. Segundo Maciel (2003) uma entre várias definições de locomotividade é o conhecimento e o controle do deslocamento do corpo em relação ao ambiente. Esta definição deve ser ampliada para incluir uma lembrança de "onde estou, o que estou fazendo, aonde vou", em relação aos lugares, coisas e outras pessoas.

Esse artigo tem por objetivo apresentar a proposta de desenvolvimento de um artefato eletrônico para o usuário PDV para lhe fornecer informação sobre caminhos e barreiras enfrentados na sua mobilidade em ambiente indoor. Este orienta a pessoa "caminhar" mentalmente em um espaço físico previamente estudado, sem a necessidade de tê-lo conhecido presencialmente. Ele foi desenvolvido em computador pessoal utilizando o Jogavox, editor de jogos educacionais que executa sob o sistema computacional Dosvox, desenvolvido para uso de computadores por PDV. Para servir de ambiente indoor foi escolhido o primeiro pavimento da Biblioteca Central (BCE) da Universidade de Brasília (UnB).

\section{A CIÊNCIA DA INFORMAÇÃO E A DEFICIÊNCIA VISUAL}

Borko (1968) declara que após o Instituto Americano de Documentação resolver mudar seu nome para Sociedade Americana para a Ciência da Informação (CI), seus membros 


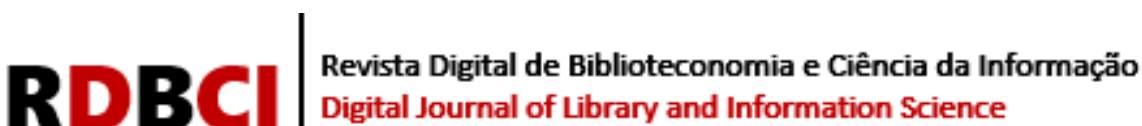

foram obrigados a explicar o que é a Ciência da Informação e o que faz seu cientista. Segundo ele esse termo está entre nós há algum tempo e é a disciplina que investiga as propriedades e o comportamento da informação, as forças que governam seu fluxo e os significados do processamento manual e mecânico, para identificar suas características e propriedades com o objetivo de melhorar a acessibilidade e usabilidade da informação, independente da pessoa que possa fazer uso dela.

A Ciência da Informação deve ser vista por uma visão macroscópica, sob uma ótica global por fazer parte de todas as disciplinas e especialmente sob uma visão microscópica, por ser demanda de cada ser humano. Ela desempenha um papel importante na sociedade, não somente na área humana, mas em outras áreas.

Segundo Saracevic (1996, p. 54) os papéis econômico e social de toda e qualquer atividade de informação estão se tornando mais e mais pronunciados; sua importância estratégica ultrapassa o nível da cooperação regional e global, em direção ao desenvolvimento nacional e ao progresso social, bem como em direção aos avanços organizacionais e vantagens competitivas.

De acordo com Capurro e Hjorland (2007) devemos nos ater à inclusão dos processos interpretativos como uma condição sine qua non dos processos de informação e esta tarefa é por essência multi e interdisciplinar. Saracevic (1995) defende que a CI é um campo dedicado à investigação científica e à prática profissional abordando os problemas da comunicação eficaz do conhecimento e dos registros de conhecimento entre todos os humanos no contexto de uso social, institucional e/ou individual da informação [...] tirando tantas vantagens quanto possível da moderna tecnologia da informação.

\subsection{A deficiência visual no Brasil}

A lei 13.146 (Brasil, 2015) foi construida para assegurar e promover, em condições de igualdade, o exercício dos direitos e das liberdades fundamentais por pessoa com deficiência, com vistas à sua inclusão social e à sua cidadania. Para o Conselho Brasileiro de Oftalmologia (CBO) a atenção à PDV bem como a todo ser humano representa constantes desafios e requer atenção ininterrupta do poder público, da sociedade civil, dos profissionais envolvidos na saúde ocular e na reabilitação visual para diminuição de barreiras à obtenção de sua melhor qualidade de vida(CBO, 2018).

O público PDV é um público muito grande e pesquisas como Bastos (2017) apresentam entrevistas feitas com várias PDV defendendo que é possível observar os desafios de acesso que esses usuários enfrentam na interação com os ambientes informacionais digitais, para que seja reforçada a responsabilidade dos profissionais da informação em lhes dar atenção. Bernardo et al.(2013) defendem que a CI por meio do estudo de usuários permite identificar em quais pontos os serviços de informação possam estar deixando de atender aos usuários PDV e suas particularidades, demonstrando o que é necessário ser modificado, contribuindo assim para que a inclusão e o acesso à informação sejam maiores. Outros autores também tratam da questão como muito importante:

Fornecer a informação à PDV é essencialmente peculiar, diferente das outras deficiências, posto que a maioria das Tecnologias Assistivas são desenvolvidas com uma característica de visualidade, tornando-se "um desafio para o acesso de pessoas cegas [...] já que tais sistemas não são construídos a partir do princípio da acessibilidade universal. Pessoas cegas passam a necessitar de outras ferramentas que possibilitem esse acesso (MADEIRA-COELHO et al., 2016, p. 3)”. 


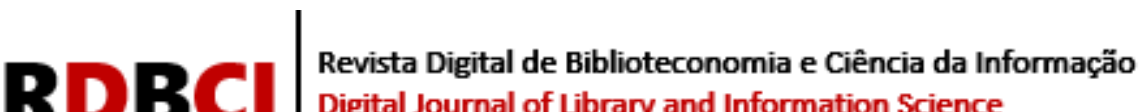 \\ Digital Journal of Library and Information Science}

\subsection{Estudo do usuário pessoa com deficiência visual}

Segundo Cunha, Amaral e Dantas (2015) a demanda informacional do usuário é identificada pelo processo de descobrir, analisar, documentar e verificar as restrições que refletem as necessidades do usuário para um artefato que sirva à uma finalidade. Estes pesquisadores fazem um paralelo entre o estudo do usuário da informação e a gestão de requisitos afirmando que na Engenharia de Software a gestão de requisitos adquire sua importância de acordo com a sua perspectiva de ação ao se preocupar em incorporar o usuário, estimulando sua participação ativa na modelagem de um sistema de informação. Declaram ainda:

[...] a Engenharia de Software nos ensina ao destacar as vantagens do envolvimento dos usuários na definição dos requisitos de um sistema de informação. É nesse sentido que essa aprendizagem, ao ser transferida para o desenvolvimento de estudos de usuários, mostra a vantagem dessa preocupação com o envolvimento dos usuários [...] Assim, os estudos de usuários assumem importância como instrumentos de planejamento e gestão, porque fornecem subsídios aos profissionais para a identificação do perfil dos seus usuários, com o objetivo de planejar serviços e produtos a serem desenvolvidos para atendê-los (CUNHA, AMARAL E DANTAS, 2015, p. 59).

Segundo Carvalho (2019) uma das categorias ou divisões que definem os estudos de usuários é aquela que estuda como buscam, usam e constroem informação visando satisfazer as suas necessidades. Juntamente com a natureza do estudo qualitativo, que é voltado para o paradigma cognitivo, procura identificar as necessidades de informação e conceber estratégias para a satisfação dessas necessidades. Bastos (2017) afirma que quanto maior o conhecimento que uma PDV tem sobre ela e sua interação com o meio, maiores serão as referências para que ela consiga obter e assim ampliar sua compreensão sobre o mundo, o que permite observar a contribuição dos estudos sócio cognitivos nesse campo, pois permitem ampliar a visão sobre o desenvolvimento de interfaces e recursos digitais mais inclusivos e democráticos para a PDV sob a análise das suas necessidades informacionais.

Como um novo paradigma para o estudo de usuários, os estudos de práticas informacionais surgem a partir de uma crítica aos estudos sobre comportamento informacional e necessidades de informação (BERNARDO, MUÑOZ e SILVA, 2020). Já os pesquisadores De Lucca, Pinto e Vitorino (2019) relacionam os estudos de usuários e de comportamento informacional com os processos de necessidades e usos da informação, afirmando que os estudos de comportamento e de necessidades relacionam a informação ao contexto.

Considerando este quadro, conhecer as necessidades dos usuários com deficiência visual além das características apresentadas anteriormente, apresenta um cuidado maior pelo fato de que os meios de informação disponibilizados não são os mesmos, há que se preocupar com o modo com que a informação chegará à este público específico. Lima (2018) afirma que para garantir o acesso à informação é de extrema importância que as PDV tenham o seu direito garantido. Essa garantia dos direitos passa pela eliminação das barreiras utilizando desenvolvimento tecnológico e a informação por ser um produto da sociedade permite a eliminação dessas barreiras. O conhecimento causa um crescimento pessoal e as PDV podem ser seres atuantes dentro da sociedade por meio da informação.

\subsection{Acessibilidade à pessoa com deficiência visual}

A acessibilidade é tratada como um atributo essencial do ambiente que garanta a melhoria da qualidade de vida das pessoas. Na recomendação de Brasil (2019) ela deve estar 


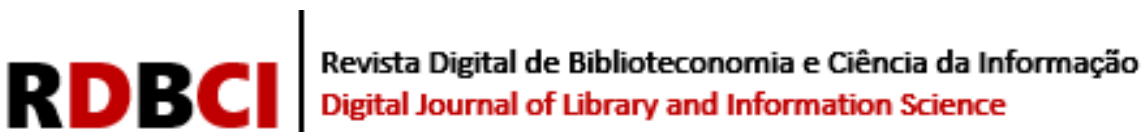

presente nos espaços, no meio físico, no transporte, na informação e comunicação, inclusive nos sistemas e tecnologias da informação e comunicação, bem como em outros serviços e instalações abertos ao público ou de uso público, tanto na cidade como no campo. Segundo Sassaki (2007) é importante fortalecer o que foi adotado em 1986 pela organização nãogovernamental 'Pessoas com Deficiência da África do Sul (Disabled People South África DPSA)', ao definirem o lema "Nada Sobre Nós, Sem Nós". Este foi um manifesto para conscientizar a humanidade de que nenhuma ação sobre pessoas com deficiência deve ser construída sem a participação das mesmas.

A Secretaria Especial dos Direitos da Pessoa com Deficiência do governo federal afirma que é um tema ainda pouco difundido, apesar de sua inegável relevância. Está disponibilizado em seu site o documento Manual de Adaptações de Acessibilidade (Brasil, 2016) que orienta e subsidia os gestores dos órgãos e entidades da administração pública federal direta e indireta na viabilização de implantação da acessibilidade nas edificações de uso público, em especial no que rege a Norma Brasileira ABNT 9050 e demais legislações. O manual prevê para estes órgãos a elaboração de laudo de acessibilidade, a contratação de projetos (se necessário) e do orçamento da obra e a contratação da execução dos serviços comuns de engenharia.

\subsection{Barreiras para a mobilidade indoor da pessoa com deficiência visual}

A mobilidade indoor é o ato da pessoa se locomover em ambiente fechado envolvendo para isso ações prévias como mapear visualmente o ambiente, decidir qual trajetória tomar considerando seu ponto de partida e seu ponto desejado de chegada, mesmo que a distância seja muito curta (Bernardo, Muñoz e Silva, 2020). Um obstáculo durante o trajeto por menor que seja, se torna um desafio a ser superado e exige da pessoa muitas operações mentais, incluindo a captura voluntária (ou não) de informações no ambiente, a sua interpretação, segundo os seus conhecimentos e habilidades do processo decisório do que fazer, ou não fazer, naquela ocasião específica (ABRAHÃO et al., 2009).

Uma tarefa como uma caminhada depende das condições do quanto o espaço de trabalho facilita a apreensão das informações ou a busca por novos dados acrescidos de disposição e disponibilidade de recursos para exercer essa tarefa. Intuitivamente e de forma mecânica a pessoa identifica se conseguirá ou não transpor o obstáculo. Para as PDV foi realizada pesquisa que as ajudam em sua mobilidade e no seu reconhecimento de pontos específicos em ambientes fechados, com apoio da integração de tecnologias de identificação por radiofrequência e dispositivos móveis, descrita no trabalho de Roque et al. (2017).

Da mesma forma Pereira Filho e Oliveira (2015) apresentam pesquisa que utiliza aplicativo mobile para navegação e contém o mapa do ambiente, onde os obstáculos e barreiras são identificados por diversas etiquetas eletrônicas espalhadas pelo ambiente, indicando ao usuário a sua localização. Essas etiquetas consistem de um circuito integrado onde os dados são armazenados e podem ser instaladas em objetos espalhados pelo ambiente. Apesar das soluções desenvolvidas, ainda há vários desafios a serem superados a fim de que as aplicações de navegação indoor sejam inclusivas para uma PDV em suas rotinas mais simples.

\subsection{Tecnologia Assistiva para a pessoa com deficiência visual}

As iniciativas específicas de desenvolvimento de Tecnologias Assistivas geralmente começam por pesquisadores, entusiastas e organizações (SENS e PEREIRA, 2015). Existem meios para garantir a inclusão de PDV em vários ambientes que podem ser tomados como exemplo para proporcionar acessibilidade. 


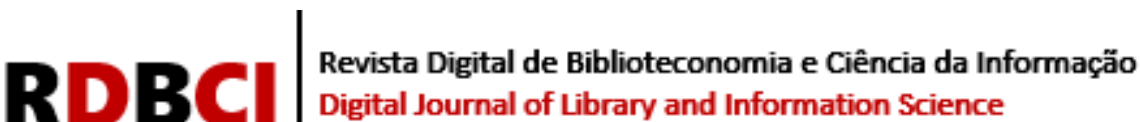

Bastos (2017) identifica em sua pesquisa que as necessidades de informação da PDV não se diferenciam dos demais usuários. $\mathrm{O}$ que os distingue são os suportes de informação e tecnologias utilizadas para obter acesso à informação, os quais não devem impor e ter nenhuma barreira excludente. Defende que apesar de existirem vários caminhos que promovam acesso à informação há também inúmeras dificuldades postas no caminho da PDV que a impedem de alcançar a informação desejada e, por conseguinte, aspectos importantes relacionados à informação, como a educação, o trabalho e o lazer.

Segundo Sá, Campos e Silva (2007), o trabalho com alunos com baixa visão baseia-se no princípio de incentivar o pleno aproveitamento da visão potencial e dos demais sentidos, bem como na superação de dificuldades e conflitos emocionais. As escolhas e níveis de adaptação dos recursos a serem usados em cada caso devem ser definidos a partir da conciliação de vários fatores. Entre eles estão necessidades específicas, diferenças individuais, idade, preferências, interesses e habilidades que determinarão as modalidades de ajustes e atividades mais apropriadas. Assim se percebe a importância de entender todo o contexto e todas suas variáveis para que não haja prejuízo para a parte das PDV. Procurando observar todos os aspectos de muitos ângulos diferentes para que a acessibilidade seja completa.

Com cada vez mais presença no mundo, a tecnologia tem sido utilizada nas áreas de saúde, comunicação, educação e outras, os jogos eletrônicos foram inseridos em várias mídias, mostrando utilidades além de diversão. Jacko (2012) afirma que muitos pesquisadores ainda estão trabalhando em designs inovadores de telas, dispositivos de entrada, saída de multimídia, kits de ferramentas de programação e modelos preditivos de desempenho do usuário que reforçaram a interação humano-computador.

A cada dia novas tecnologias são desenvolvidas para melhorar a experiência dos usuários. No entanto, de acordo com Sens e Pereira (2015) apesar do crescimento exponencial da indústria digital, pessoas com deficiência fazem parte do público consumidor que não é atendido com plenitude. Elas possuem dificuldades de encontrar produtos que se adéquem às suas condições físicas, cognitivas ou motoras. Muitas afirmam a importância da acessibilidade, inclusive no ponto de vista do mercado. No entanto, na prática essa preocupação inclusiva não é verificada.

Os pesquisadores Main et al. (2016) apresentam pesquisas que demonstram como alunos com deficiência poderiam utilizar a tecnologia desenvolvida para o mercado em geral e como ela pode ajudá-los no princípio da normalização, que defende que pessoas com deficiência devem ter a oportunidade de compartilhar experiências dos mesmos contemporâneos. Conclui que esses alunos estavam positivamente envolvidos com a tecnologia e as observações permitiram que todos percebessem mudanças incrementais no desempenho dos alunos com deficiência.

\section{DESENVOLVIMENTO DO ARTEFATO NO DOSVOX}

O desenvolvimento de artefato descrito neste artigo foi executado a partir dos resultados apresentados da pesquisa de Bernardo, Muñoz e Silva (2020) que apresenta a validação de um instrumento de coleta de dados feita com quarenta e oito PDV. Nela foi obtida a percepção do uso do Dosvox para permitir acesso à informação sobre caminhos e barreiras a enfrentar na mobilidade indoor na Biblioteca Central da Universidade de Brasília, estabelecendo uma relação entre as necessidades de informação da PDV na questão da mobilidade e a utilização de artefato a ser desenvolvido no Jogavox para atender estas necessidades.

Fundamentado nesta pesquisa os autores desenvolveram o artefato utilizando o 


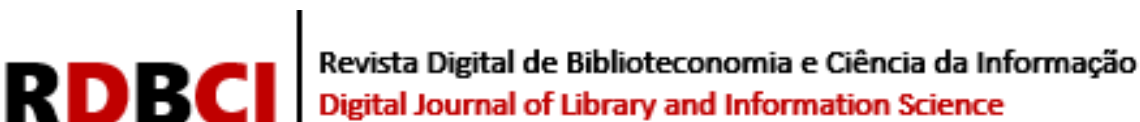

Jogavox dentro do sistema computacional Dosvox, seguindo as orientações apresentadas em Borges (2019) e NCE/UFRJ (2019b).

\subsection{O Sistema computacional Dosvox}

Dosvox é um sistema criado em 1993 para microcomputadores que utiliza um sintetizador de voz em Português brasileiro, sendo que a síntese de textos pode ser configurada para outros idiomas. Essa sintetização de voz permite que as PDV usem computadores e tenham independência para estudar, trabalhar e se divertir. A maioria das mensagens sonoras emitidas pelo Dosvox é feita em voz humana gravada, seu código é aberto, permitindo sua edição para criar novas funcionalidades.

O Núcleo de Computação Eletrônica da Universidade Federal do Rio de Janeiro (NCE/UFRJ) (2019a) apresenta a estimativa de que existam cerca de 100.000 pessoas de todas as classes sociais e em todo Brasil que façam ou tenham feito uso do Dosvox. Afirma também que

\begin{abstract}
Com a leitura que o computador faz da tela por meio de falas sintéticas, qualquer pessoa cega ou não consegue interagir com ele, usando um conjunto pequeno de teclas de atalho, que proporciona acesso a leitura e escrita, acesso as informações e mídias disseminadas pela Internet, utilização de jogos eletrônicos adaptados, além do controle da vida pessoal por meio de muitos utilitários de apoio à vida diária. NCE/UFRJ (2019a).
\end{abstract}

Na pesquisa de Silva (2017) é apresentada uma descrição da criação do Dosvox. Nessa dissertação que apresenta estudo da interação entre alunos da rede pública do Distrito Federal e os jogos digitais adaptados presentes no Dosvox, o autor apresenta as dificuldades de utilização desses jogos e a sua relação com a memória de trabalho, como a atenção e a tomada de decisão da PDV. Segundo ele, para atender à demanda por programas que permitam a PDV acessar inúmeros recursos tecnológicos foram criados programas que permitem o acesso e a interação com as redes sociais, tais como o Googlevox, que torna mais acessível as buscas realizadas pelas PDV ao Google, o Twitox que é uma versão da rede social Twitter e o Voxtube que é um acesso acessível ao site de vídeos YouTube.

No Instituto Tércio Pacitti, que pertence ao Núcleo de Computação Eletrônica da Universidade Federal do Rio de Janeiro (NCE/UFRJ), berço do Dosvox, existem projetos voltados para proporcionar à pessoas com deficiência novas oportunidades com base na tecnologia de informática, e entre esses projetos os voltados para a PDV. São eles: Projeto Dosvox - computação para deficientes visuais; Proyecto Dosvox en español; Projeto Braille Fácil - Impressão Braille Computadorizada do Instituto Benjamin Constant; Projeto MecDaisy, que são livros digitais sonoros para deficientes visuais; Jogavox, sistema para criação de jogos pegagógicos inclusivos; Projeto Musibraille - automatizando a produção musical por deficientes visuais por meio do Braille; TecnoAssist - Aperfeiçoamento em Atendimento Educacional Especializado para o estudante com deficiência visual; I Forum de Tecnologia Assistiva; II Forum de Acessibilidade e Tecnologia Assistiva; Curso para Multiplicadores de Dosvox na Perspectiva da Educação Inclusiva - plataforma Moodle; Braille para Professores uma abordagem prática com Tecnologia (NCE/UFRJ, 2019a). Silva (2017) apresenta um quadro com todos os jogos do sistema Dosvox versão 5.0. 


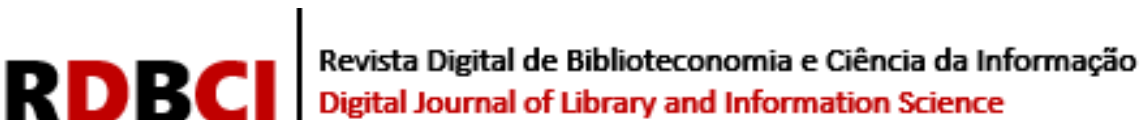

\subsection{Editor de jogos educaconais Jogavox}

Considerado como um projeto, o Jogavox é um aplicativo que funciona dentro do Dosvox, desenvolvido pela equipe da NCE/UFRJ (2019b) para que professores das escolas públicas do Rio de Janeiro possam produzir jogos pedagógicos multimídia que sejam contextualizados para serem aplicados em projetos de inclusão de alunos com deficiência visual. Para desenvolver jogos pedagógicos é necessário que o docente conheça sua tecnologia e sua metodologia. Sua ideia central é permitir que o docente desenvolva os jogos educativos que irá utilizar, decidindo que conteúdos trabalhar e que temáticas utilizar. Por ser fácil de usar, possibilita que pessoas com pouco conhecimento em informática desenvolvam seus próprios jogos.

Por possuir orientações como instalar, criar jogos a partir de roteiros e como criar jogos a partir das janelas de edição, além das videoaulas, o Jogavox permite criar muitas possibilidades para um objetivo. A opção de inserir arquivos de multimídia aumenta o interesse pelo artefato desenvolvido e se torna um produto interessante para a pessoa com qualquer nível de deficiência visual, sendo também agradável para as pessoas sem deficiência visual.

Silva (2017) apresentou uma proposta de classificação dos jogos digitais, baseada em classificações anteriores, que leva em consideração as dimensões cognição, socialização, afetividade, motivação, criatividade e psicomotricidade. A partir daí criou as categorias: jogos digitais cognitivos, jogos digitais de socialização, jogos digitais afetivos, jogos digitais motivacionais, jogos digitais criativos e jogos digitais de psicomotricidade. Para ele a funcionalidade de criação e edição do Jogavox explora a criatividade dos usuários ao extremo, pois permite que sejam criados jogos e também que os jogos já criados sejam melhorados.

Uma outra pesquisa foi realizada em escola pública do Rio de Janeiro, quando Robalinho e Costa (2019) apresentam o processo de construção de um jogo digital criado de forma participativa com alunos com deficiência visual utilizando o Jogavox. A pesquisa teve o objetivo de obter a percepção dos alunos com relação à validade do Jogavox considerando sua usabilidade e ludicidade, promovendo a inclusão, bem como estimular a utilização de recursos lúdicos para a aquisição de conhecimento.

Sobre a utilização do Sistema Dosvox e do programa Jogavox, os pesquisadores entendem que ele atende ao propósito de ser inclusivo, uma vez que suas informações parecem claras e o modo de interação se mostrou bem simples o que viabiliza que pessoas com outras deficiências e pessoas que não dominam a informática possam fazer uso do mesmo. Afirmam a crença no poder transformador do sistema e reforçam a expectativa de que outras pessoas se sintam impelidas a desenvolver outras propostas inclusivas, criativas, inovadoras e significativas na busca de uma educação cada vez mais emancipadora, autônoma, crítica e para todos.

\subsection{A Biblioteca Central da UnB como pano de fundo para desenvolvimento do artefato}

O espaço definido como experimento para a mobilidade indoor foi o pavimento térreo da Biblioteca Central da Universidade de Brasília (BCE/UnB), localizada no Distrito Federal. Com o conhecimento de que a PDV pode ganhar independência funcional por meio de treinamento em orientação e mobilidade é possível identificar que o uso criativo de ambientes de navegação virtual interativa possa fornecer flexibilidade e complementar esse tipo de treinamento (CONNORS et al.,2013).

A BCE tem como missão realizar processos de gestão da informação necessária das atividades de ensino, pesquisa e extensão e delas resultantes, em uma perspectiva integrada, para a formação de cidadãos éticos e qualificados para o exercício profissional e empenhados 


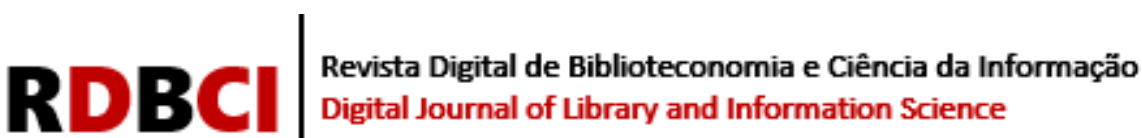

na busca de soluções democráticas para questões nacionais e internacionais, por meio de atuação de excelência (BCE, 2019).

Um mapa tátil é um recurso que possibilita à PDV ter percepção mais concreta do espaço geográfico, que desenvolve a orientação e a mobilidade na dificuldade visual e por meio do tato (SILVA JUNIOR, 2018). A Figura 1 apresenta um exemplo de mapa tátil disponibilizado ao público no primeiro pavimento de uma agência bancária brasileira. Nele estão os nomes de todos os locais do primeiro pavimento e abaixo da orientação dos locais existe a tradução em braile. Por meio tátil a pessoa identifica naquele piso do estabelecimento quais os seus pontos de acessibilidade, que lhe permite "caminhar" mentalmente, orientando por onde deva ir. A biblioteca não possui mapa tátil conforme é orientado pela Norma brasileira ABNT 9050 (ABNT, 2015), não possui descrição sonora dos seus espaços físicos, mas possui como item de acessibilidade física uma rampa de acesso na entrada e piso tátil em todo o pavimento térreo.

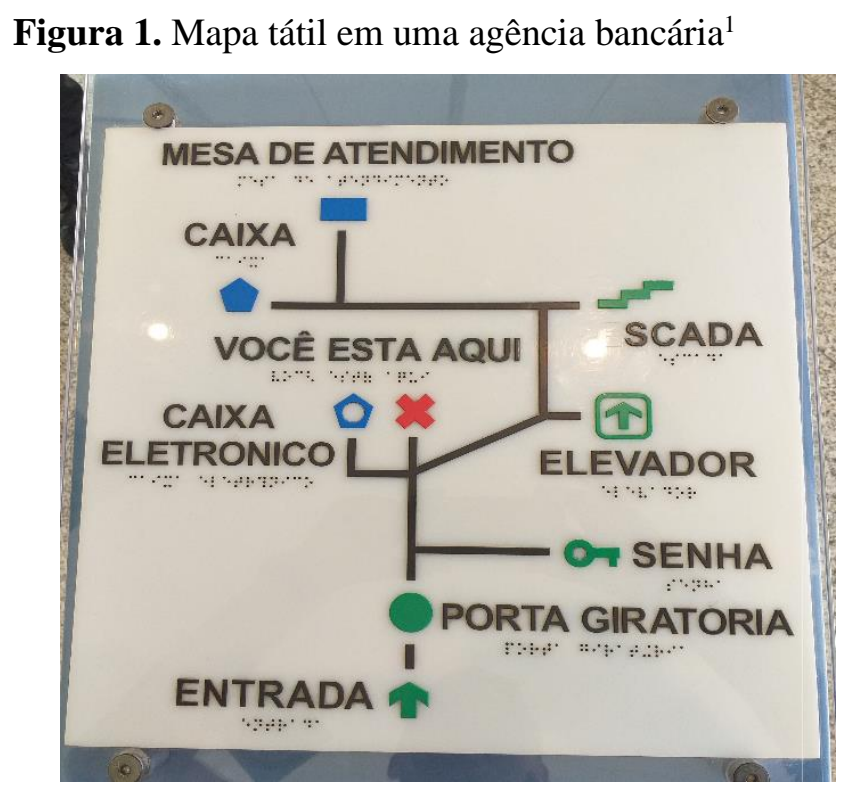

Fonte: os autores

Foi desenvolvido um roteiro com o caminho a ser cumprido pelo usuário. Este roteiro tem o perfil de um fluxograma, com a diferença que a orientação não é TOP-DOWN mas sim DOWN-TOP. A fase inicial começa na parte de baixo para que seja dada a impressão de ingresso em um ambiente e a parte de cima representa o fim da "caminhada". Ao utilizar o artefato a pessoa que estiver operando é levada a imaginar que está em um ponto inicial, um ponto de partida. Foi pensada toda ação possível em que o usuário possa se envolver ao desejar trilhar o caminho. Partiu-se da premissa que a pessoa está em um ponto e deseja ir para outro ponto, portanto o artefato traz todas as orientações de como ela deve agir para atingir o objetivo.

$\mathrm{O}$ texto sintetizado foi criado como uma conversa interativa entre o artefato e o operador. Apesar do Dosvox permitir que se crie artefatos com a opção de mais do que duas saídas, este artefato foi criado com respostas binárias, dando a opção de o operador escolher uma saída ou outra. Cada caminho da bifurcação leva a outra bifurcação, até que chegue ao seu final, com a possibilidade de começar tudo novamente e escolher um caminho ainda não trilhado. Cada caminho corresponde a mais uma fase a ser vencida. Nesta bifurcação aparece

\footnotetext{
${ }^{1} \mathrm{Na}$ imagem acima é apresentado um mapa tátil do andar térreo da agência, com ponto inicial na entrada, depois a porta giratória e outros acessos, como elevador, caixa eletrônico e escada.
} 


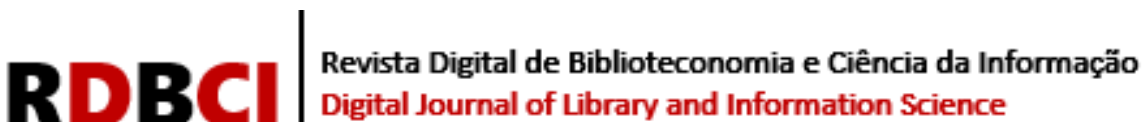

uma outra informação de onde o operador está e o que ele deve fazer para seguir aquele caminho.

Ao concluir cada fase o artefato apresenta uma frase comemorativa, incentivando a continuar o percurso. Desta forma a ação passa a imagem de competição, um alvo a ser atingido. O fluxo da costura obedeceu ao trio RESPOSTA-ACERTO-ERRO. Na figura 2 é apresentado o fluxo do artefato criado para a mobilidade na BCE.

Figura 2. Fluxo do artefato desenvolvido ${ }^{2}$

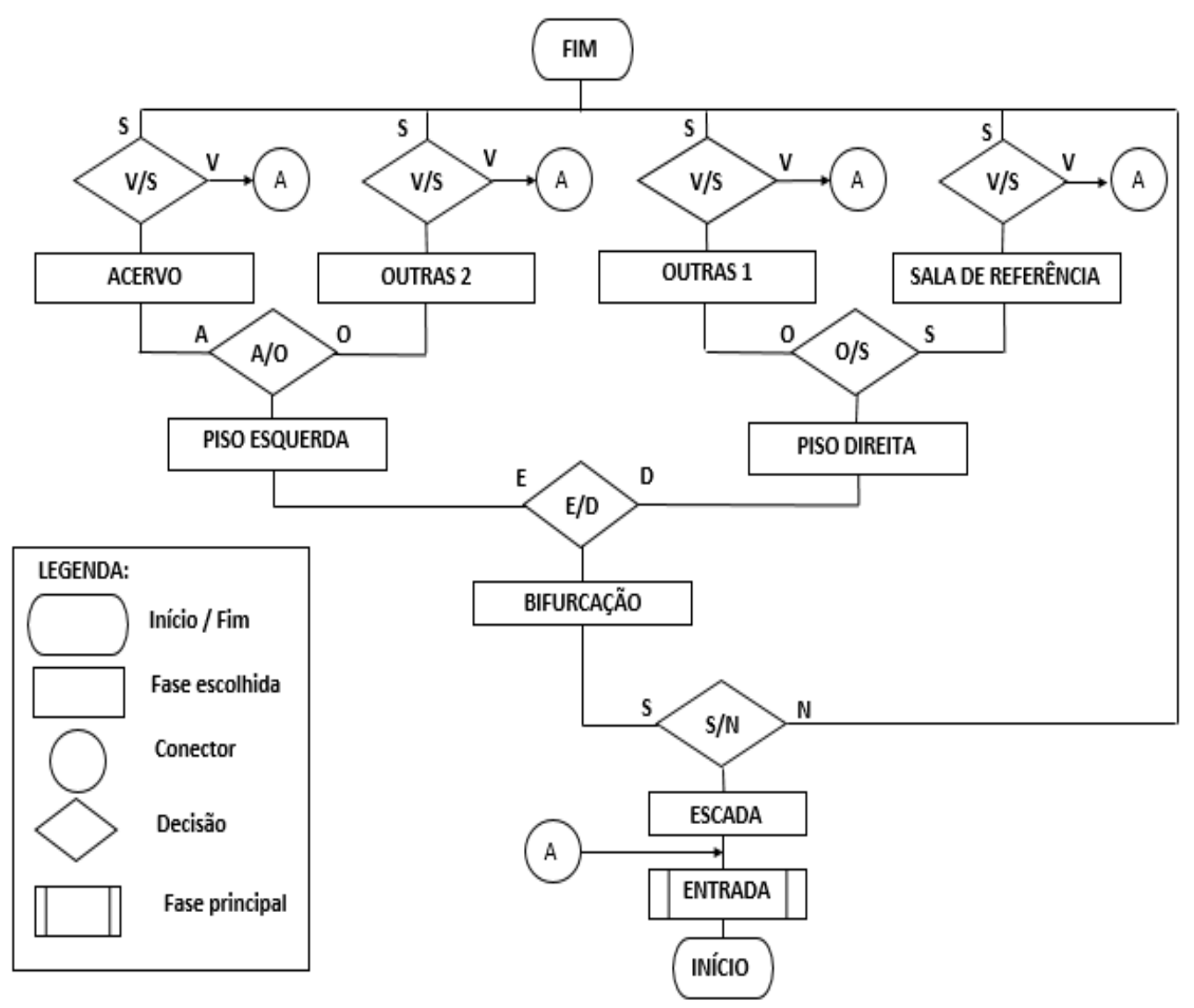

Fonte: os autores

No fluxo do artefato desenhado constam as seguintes opções de caminhada pela Biblioteca Central da UnB: S - Sim para ir para a bifurcação; $\mathbf{N}$ - Não para encerrar o jogo; $\mathbf{E}$ Caminhar pelo piso Esquerdo; D - Caminhar pelo piso Direito; O - Outras opções; $\mathbf{S}$ - Acessar informações sobre a sala de referência; A - Acessar informações sobre a sala de Acervo; V Voltar à escada de entrada da biblioteca; $\mathbf{S}$ - Sair do artefato. Foram obedecidos certos limites humanos no quesito da comunicação, considerando que a mente humana tem capacidade limitada de processamento de informações da memória de trabalho (SANTANA, 2019). A intenção foi evitar sobrecarregar o operador com muitos dados tais como: rumo a tomar, escada a subir/descer, portas a abrir, obstáculos a superar.

Foram criados blocos com até cinco frases informativas e a partir de cada um desses blocos existe a possibilidade de entrar em mais um novo bloco, sendo que dentro dele são fornecidas mais outras cinco informações para que não sejam passadas em um só momento,

\footnotetext{
${ }^{2} \mathrm{Na}$ imagem acima é apresentado o fluxo do artefato, com ponto inicial na entrada da biblioteca, depois acesso à escada, depois a bifurcação para o lado esquerdo e direito. A partir desses pontos existem acessos para outros pontos.
} 


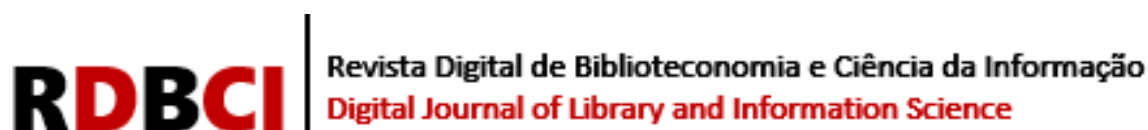

evitando acúmulo de informações que leva à perda.

A informação sendo fornecida de maneira hierárquica funciona melhor do que se for fornecida de maneira linear. Isso faz uma referência a metadata, que trata de um dado que traz informações sobre mais outros dados, garantindo assim um contexto mais palatável para o usuário. Para tornar o artefato mais interessante foram adicionados sobre o roteiro alguns itens de multimídia como fundo musical e onomatopeias tornando-o mais sensorial, porque a PDV tem uma influência auditiva muito forte, posto que o som para ela é como se fosse a cor para a pessoa que enxerga (KOHLER; FOERSTE, 2014).

O artefato foi denominado de "Visita virtual à biblioteca" e foi desenvolvido em junho de 2019. Por ser um artefato que faz audiodescrição de um ambiente físico, descrevendo toda a instalação física, pode ser categorizado como um mapa auditivo. Foram tiradas fotografias dos acessos do pavimento térreo com autorização por escrito da administração da biblioteca, para serem utilizadas no artefato desenvolvido. Este apresenta informações para a pessoa tais como chegar a determinados pontos da biblioteca e quais obstáculos e barreiras a serem vencidas. Os pontos são fases do software e foram-lhe atribuídos os seguintes nomes: 'Entrada, Escada, Bifurcação, PisoDireita, Sala_referencia, Outras1, PisoEsquerda, Acervo, Outras2, Sair_geral, Saida'.

A figura 3 apresenta imagem da primeira fase do artefato que recebeu o nome "Entrada" e traz a fotografia da fachada da BCE com mensagem de boas-vindas e a opção de iniciar a "caminhada" por meio do artefato. Junto com a apresentação da figura 3 é narrado o texto utilizando o sintetizador de voz do Dosvox: "Bem-vindo à Biblioteca Central / Universidade de Brasília / Aperte ENTER para começar". Ao teclar [Enter] o artefato inicia a segunda fase.

Figura 3. Tela da primeira fase 'Entrada' com a fachada da $\mathrm{BCE} \mathrm{E}^{3}$

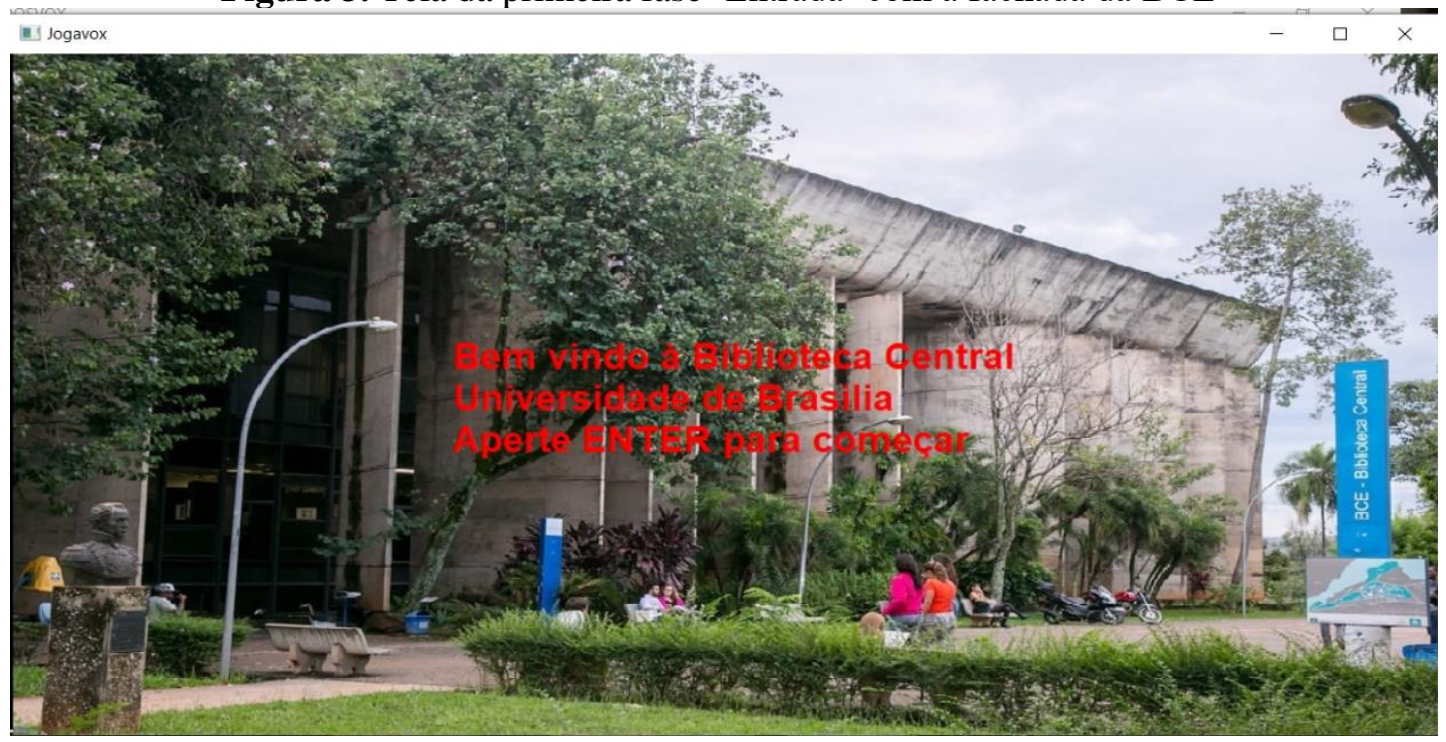

Fonte: os autores

Já a figura 4 apresenta uma fotografia da entrada da BCE, que faz parte da segunda fase chamada "Escada". Nesta figura é apresentada a escada de acesso à biblioteca, que possui 8 degraus. Em cada degrau está pintada a lombada de vários livros famosos, como os clássicos 'O antagonista' ou 'Cem anos de solidão'. No final do oitavo degrau se encontram três catracas de acesso à biblioteca. À esquerda da escada está uma rampa com piso emborrachado.

\footnotetext{
${ }^{3} \mathrm{Na}$ imagem acima é apresentada a fachada da Biblioteca Central da Universidade de Brasília, com alguns alunos sentados em bancos em frente, tendo ao fundo o totem com o nome da biblioteca.
} 


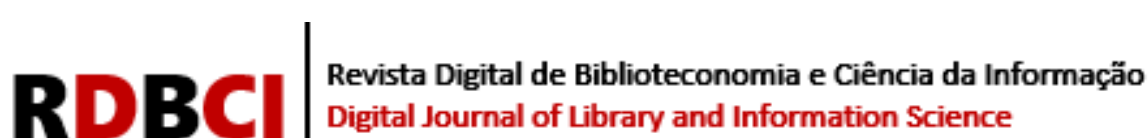

Junto com a apresentação da figura 4 é narrado o texto utilizando o sintetizador: "Você está na escada da entrada principal / Suba 8 degraus para chegar na portaria / Cadeirante pode ir pela rampa à esquerda / O piso é emborrachado! / No final, existe uma catraca de entrada. / Aperte S se você passou pela catraca / Aperte $N$ se quiser sair". As possíveis respostas são "S" e "N". Caso a opção seja a primeira o artefato encaminhará o operador para a fase "Bifurcação", caso seja a segunda ele será encaminhado para a fase "Sair_geral". Em caso de erro será encaminhado para a fase "Escada".

A parte visual do artefato é necessária, pois o mesmo poderá ser operado também por pessoas sem deficiência visual, pessoas com baixa visão e pessoas sem deficiência visual acompanhantes de PDV, caracterizando assumindo assim um papel de artefato inclusivo. Devido a limitações deste artigo não é possível apresentar todo o fluxo criado bem como as outras sete fotografias equivalentes às demais fases e respectivos textos, sintetizados pelo Dosvox. Após "caminhar" mentalmente por todos os espaços físicos do pavimento térreo da biblioteca acessando todas as funcionalidades, a pessoa tem uma "visão" de como é o mapa físico deste ambiente, posto que foi criada uma narrativa de como chegar a cada um dos pontos apresentados.

A concepção da ideia se deu pelo fato de que uma pessoa sem deficiência visual ao desejar visitar um local que não seja um ambiente interno e que seja desconhecido para ela, tem o recurso de acessar a internet e consultar o mapa deste local. A partir dessa consulta tem uma noção de como é este lugar, o que deve fazer para acessá-lo, quais as barreiras e dificuldades que enfrentará para chegar ao local.

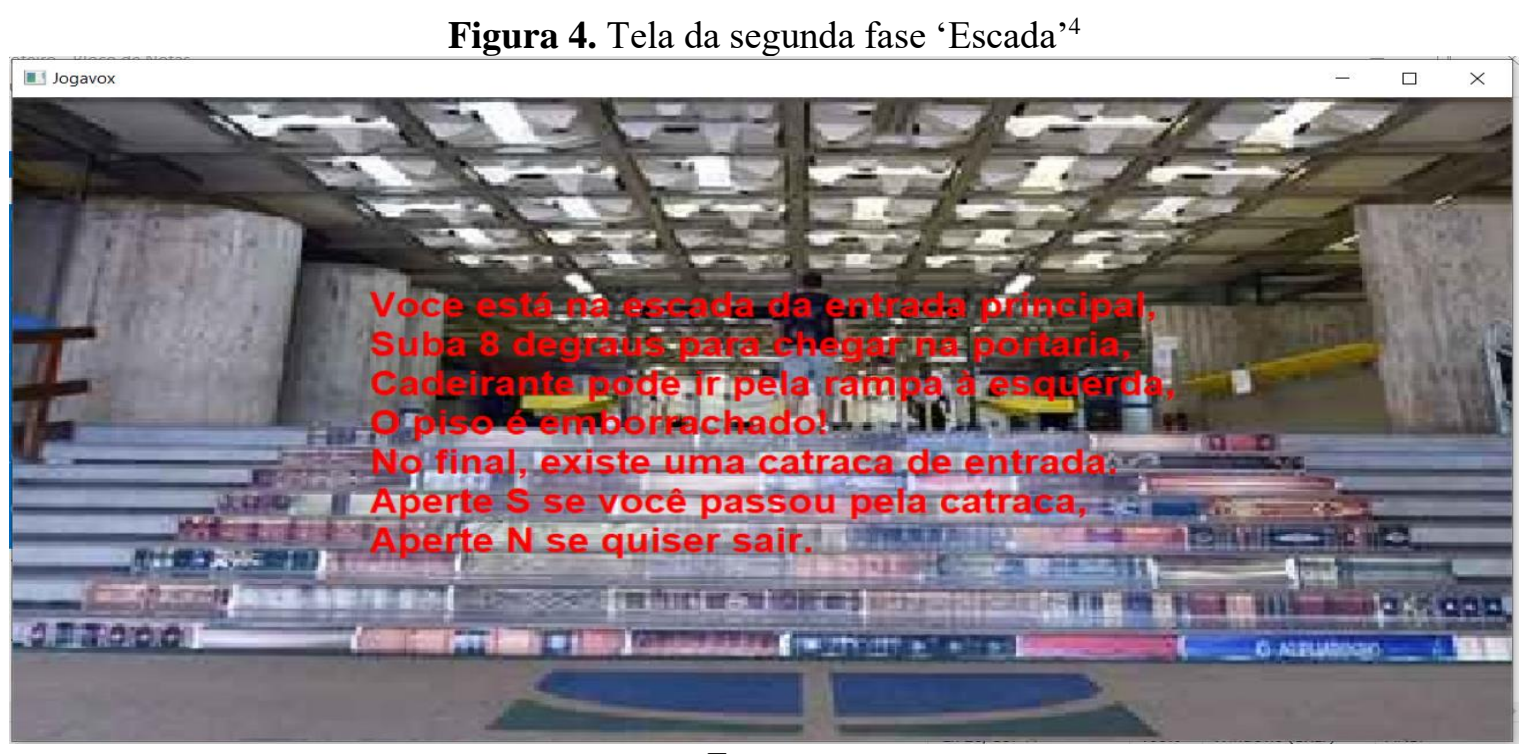

Fonte: os autores

Ao desejar caminhar por um ambiente indoor a PDV além de não poder fazer uso do mapa pela internet ou qualquer outro recurso visual, ela não possui nenhum recurso que a oriente por onde deva entrar ou sair, quais as barreiras, quais e quantos são os obstáculos em sua desejada caminhada.

\footnotetext{
${ }^{4} \mathrm{Na}$ imagem acima é apresentada a escada da entrada da Biblioteca Central da Universidade de Brasília, com oito degraus, tendo em cada um nome de livros famosos.
} 


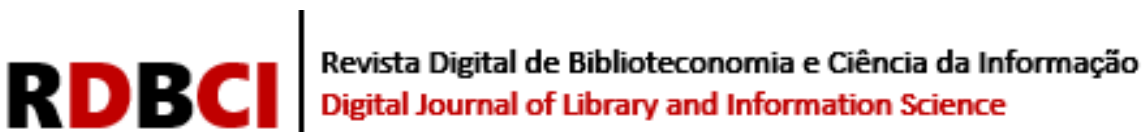

\section{CONCLUSÃO}

Para dar continuidade à pesquisa está prevista a execução de entrevistas com PDV que fizerem uso do artefato desenvolvido, para avaliar o grau de satisfação em relação à informação fornecida. Estão previstos ainda a criação do modelo de referência para desenvolvimento do artefato eletrônico, o refinamento do artefato e do modelo, considerando a opinião das pessoas consultadas; a validação do artefato por meio de um grupo focal composto por PDV que não conheçam o espaço físico definido no artefato e o refinamento final do artefato e do modelo. Segundo Sassaki (2007) a acessibilidade física e a acessibilidade à informação por PDV são temáticas que devem ser discutidos com a participação delas, pois são alvos do produto a ser desenvolvido. Nada sobre pessoas com deficiência deve ser feito sem a participação delas.

A partir do protocolo de estudos apresentado neste artigo se espera que seja possível conduzir investigações mais precisas para orientar os desenvolvedores de demais artefatos acerca das necessidades e especificidades da PDV. A partir da disponibilização de mais artefatos construídos, se entende que o processo de inclusão seja ampliado, permitindo seu uso para fins de aprendizagem, treinamento, orientação ou mesmo entretenimento, garantido os seus direitos.

Assim, além da condução das próximas etapas empíricas do estudo, se considera importante o compartilhamento detalhado do referencial teórico e metodológico que orientou a construção dos instrumentos e da abordagem do presente estudo, visando a ampliação da comunicação científica sobre o tema e apoiando outros estudos relacionados ainda em fase de planejamento.

\section{AGRADECIMENTOS}

Os autores deste artigo gostariam de agradecer às pessoas com deficiência visual que participaram da pesquisa, aos funcionários da Biblioteca Central (BCE) da Universidade de Brasília (UnB), ao Professor Dr. José Antonio dos Santos Borges e ao Instituto Tércio Pacitti de Aplicações Computacionais da Universidade Federal do Rio de janeiro (UFRJ), responsáveis pela criação do Dosvox e das pesquisas desenvolvidas para aumentar a inclusão.

\section{REFERÊNCIAS}

ABRAHÃO, Julia et al. Introdução à ergonomia: da prática à teoria. São Paulo, SP: Ed. Blucher, 2009. ISBN: 9788521204855.

AGÊNCIA IBGE NOTÍCIAS. Novo coronavírus. Censo é adiado para 2021 e coleta presencial de pesquisas é suspensa. Redação de 27 maio 2020. Disponível em:

https://agenciadenoticias.ibge.gov.br/agencia-noticias/2012-agencia-denoticias/noticias/27160-censo-e-adiado-para-2021-coleta-presencial-de-pesquisas-e-suspensa. Acesso em: 02 jul. 2020.

ASSOCIAÇÃO BRASILEIRA DE NORMAS TÉCNICAS 9050 (ABNT). Acessibilidade a edificações, mobiliário, espaços e equipamentos urbanos. 3. ed., Rio de Janeiro, RJ. 2015. 


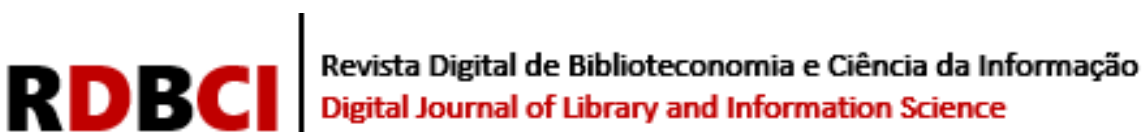

BASTOS, Karolina Vieira da Silva. Os desafios encontrados no acesso à informação digital por pessoas com deficiência visual. 2017. 174 p. Dissertação (Mestrado em Ciência da Informação) - Universidade de Brasília. Brasília, DF, 2017.

BAPTISTA, Sofia Galvão; CUNHA, Murilo Bastos da. Estudo de usuários: visão global dos métodos de coleta de dados. Perspectivas em Ciência da Informação, Belo Horizonte, v.12, mai/ago, 2007.

UNIVERSIDADE DE BRASÍLIA (BCE). Biblioteca Central. Brasília, DF. Disponível em https://www.bce.unb.br/sobre-a-bce/ Acesso em: 10 jun. 2019.

BERNARDO, Claudio Gonçalves; MUÑOZ, Ivette Kafure; SILVA, Tiago Barros Pontes e. Necessidade de informação da pessoa com deficiência visual e a proposta de artefato para sua mobilidade indoor. Pesquisa Brasileira em Ciência da Informação e Biblioteconomia, João Pessoa, PB, v. 15, n. 3, 2020, p. 77-89.

BORGES, José Antonio dos Santos. Entrevista realizada no Instituto Tércio Pacitti de Aplicaçóes Computacionais, da UFRJ. Universidade Federal do Rio de janeiro, no dia 06 de jun. de 2019.

BORKO, Harold. Information Science: what is it? California, USA: American Documentation, 1968.

BRASIL. Presidência da República. Decreto no 3.298, de 20 de dezembro de 1999. Dispõe sobre a Política Nacional para a Integração da Pessoa Portadora de Deficiência. 1999.

Brasília, DF. Disponível em: http://www.planalto.gov.br/ccivil_03/decreto/d3298.htm Acesso em: 20 mai. 2015.

BRASIL. Presidência da República. Casa Civil. Lei 13.146, de 6 de julho de 2015 - Institui a Lei Brasileira de Inclusão da Pessoa com Deficiência (Estatuto da Pessoa com Deficiência). Brasília, DF.

BRASIL. Presidência da República. Casa Civil. Decreto 8.954, de 10 de janeiro de 2017 Institui o Comitê do Cadastro Nacional de Inclusão da Pessoa com Deficiência e da Avaliação Unificada da Deficiência e dá outras providências. 2017. Brasília, DF.

BRASIL. Câmara dos Deputados. Comissão debate mapeamento das pessoas com deficiência no Brasil. Disponível em: https://www2.camara.leg.br/camaranoticias/noticias/DIREITOS-HUMANOS/575902COMISSAO-DEBATE-MAPEAMENTO-DAS-PESSOAS-COM-DEFICIÊNCIA-NOBRASIL.html. Acessado em 18 mai. 2019.

CAPURRO, Rafael; HJORLAND, Birger. O conceito de informação. Perspectivas em Ciência da Informação, Brasília, v.12, n.1, p. 148-207, jan/abr. 2007. 


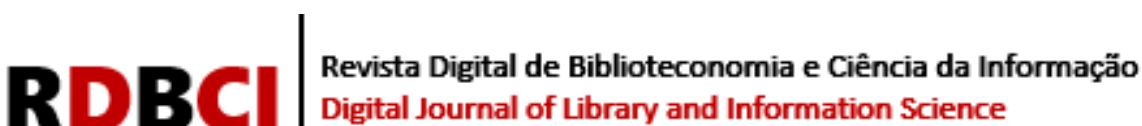

CARVALHO, Jonathas. Estudos de usuários da informação. Biblioo Cultura informacional, São Paulo, SP. Disponível em: http://biblioo.info/estudos-de-usuarios-da-informacao/ Acesso em: 06 mai. 2019.

CONNORS, Erin; YAZZOLINO, Lindsay; SÁNCHEZ, Jaime; MERABET, Lotfi. Development of an Audio-based Virtual Gaming Environment to Assist with Navigation Skills in the Blind. Journal of Visualized Experiments, 2013. Doi:10.3791/50272 (2013). Disponível em: https://www.ncbi.nlm.nih.gov/pmc/articles/PMC3641639/._Acesso em: 22 nov 2020.

CONSELHO BRASILEIRO DE OFTALMOLOGIA (CBO). In: FÓRUM NACIONAL DE ATENÇÃO À PESSOA COM DEFICIÊNCIA VISUAL, 1., São Paulo, SP. 25 maio 2018. Disponível em: http://www.cbo.net.br/novo/publico-geral/forumnacional.php Acesso em: 15 out. 2018.

CUNHA, Murilo Bastos; AMARAL, Sueli Angelica do; DANTAS, Edmundo Brandão. Manual de estudo de usuários da informação. São Paulo, SP: Ed. Atlas, 2015. ISBN 9788522498772.

DE LUCCA, Djuli Machado; PINTO, Marli Dias de Souza; VITORINO, Elizete Vieira. Educação de Usuários e Competência em Informação: interlocuções teóricas e práticas.

Revista Brasileira de Biblioteconomia e Documentação, São Paulo, SP, v. 15, n. 1, 2019, p. 170-193.

INSTITUTO BRASILEIRO DE GEOGRAFIA ESTATÍSTICA (IBGE). Censo Demográfico

2010: características gerais da população, religião e pessoas com deficiência. Censo demográfico, Rio de Janeiro, RJ, 2010. Disponível em:

https://biblioteca.ibge.gov.br/visualizacao/periodicos/94/cd_2010_religiao_deficiência.pdf Acesso em: 11 out. 2018.

JACKO, Julie. The human-computer interaction handbook: fundamentals, evolving technologies, and emerging applications. Third Edition. Florida, USA: CRC Press, Taylor \& Francis Group, 2012. ISBN 9781439829431; ISBN 978-1439829431.

KOHLER, Andressa Dias; FOERSTE, Gerda Margit Schutz. As imagens na visão do cego: experiências de quem vê com o corpo. Pró-Discente: Caderno de Prod. Acad.-Cient. Prog. Pós-Grad. Educ., Vitória, ES, v. 20, n. 2, jul./dez. 2014.

LIMA, Danna Patricia Vieira de. A mediação da informação para usuários com deficiência visual e sua transformação com o avanço da tecnologia: um estudo de caso na seção Braille da Biblioteca Pública Arthur Vianna. 2018. Trabalho de Conclusão de Curso (Graduação em Biblioteconomia) - Universidade Federal do Pará, Belém, PA, 2018.

MACIEL, Sylas Fernandes. Manual de orientação e mobilidade. O "Ir e Vir" do deficiente visual (princípios, técnicas e procedimentos). São Paulo, SP, 2003. Disponível em: http://www.deficiênciavisual.pt/txt-O_ir_e_vir_DV-manual_OM.htm. Acessado em: $13 \mathrm{dez}$. 2019. 


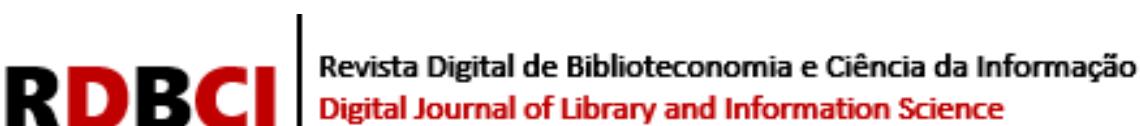

MADEIRA-COELHO, Cristina et al. Tecnologia Assistiva para acessibilidade de pessoas com deficiência visual a ambientes virtuais de aprendizagem. In: SIED - SIMPÓSIO INTERNACIONAL DE EDUCAÇÃO À DISTÂNCIA/ENPED - ENCONTRO DE PESQUISADORES EM EDUCAÇÃO À DISTÂNCIA, 2016, São Carlos, SP.

MALHEIROS, Tania Milca de Carvalho. Produtos e serviços de informação para pessoas com deficiência visual. 2019. 561 f., il. Tese (Doutorado em Ciência da Informação) Universidade de Brasília, Brasília, DF, 2019.

MAIN, Susan et al. Focus on the journey, not the destination: Digital games and students with disability. In: ISSUES IN EDUCATIONAL RESEARCH, 26(2), 315-331. 2016. Disponível em: http://www.iier.org.au/iier26/main.pdf Acesso em: 25 jun. 2016.

NUCLEO DE COMPUTAÇÃO ELETRÔNICA/UNIVERSIDADE FEDERAL DO RIO DE JANEIRO (NCE/UFRJ). Projetos de acessibilidade do Instituto Tércio Pacitti. Núcleo de Computação Eletrônica. Universidade Federal do Rio de Janeiro. 2019a. Disponível em: http://intervox.nce.ufrj.br/Acesso em: 06 jun. 2019.

NUCLEO DE COMPUTAÇÃO ELETRÔNICA/UNIVERSIDADE FEDERAL DO RIO DE JANEIRO (NCE/UFRJ). Jogavox - Editor de jogos educacionais. Núcleo de Computação Eletrônica. Universidade Federal do Rio de Janeiro. 2019b. Disponível em: http://www.jogavox.nce.ufrj.br/ Acesso em: 06 jun. 2019.

ORGANIZAÇÃO DAS NAÇÕES UNIDAS (ONU). United Nations Convention on the Rights of Persons with Disabilities. New York, USA. 2016. 28 p. Disponível em: http://www.un.org/disabilities/documents/convention/convention_accessible_pdf.pdf. Acessado em 10 out. 2018.

PEREIRA FILHO, Elzo Soares; OLIVEIRA, Luciene Chagas de. Sistema mobile de localização indoor para portadores de necessidades especiais usando NFC. In: XII CONFERÊNCIA DE ESTUDOS EM ENGENHARIA ELÉTRICA, 2015, Universidade Federal de Uberlândia, Uberlândia, MG.

PIMENTEL, Maria das Graças. Inclusão digital e usuários com deficiência visual no DF: estudo de acessibilidade na sociedade da informação. 2011. 351 f., il. Tese (Doutorado em Ciência da Informação) - Universidade de Brasília, Brasília, DF, 2011.

ROBALINHO, Bruno Cesar Soares Dile; COSTA, Christine Sertã. Jogo Digital na inclusão de alunos com deficiência visual. Informática na Educação: teoria \& prática, Porto Alegre, v. 22 , n. 1, p. 60-78, jan./abr. 2019.

ROQUE, Alexandre dos Santos et al. Mobilidade de pessoas com deficiência visual em ambientes indoor apoiada por dispositivos móveis e sistemas RFID. In: USIHC CONGRESSO INTERNACIONAL DE ERGONOMIA E USABILIDADE DE INTERFACES HUMANO COMPUTADOR, 16., 2017, Universidade Federal de Santa Catarina, Florianópolis, SC. 


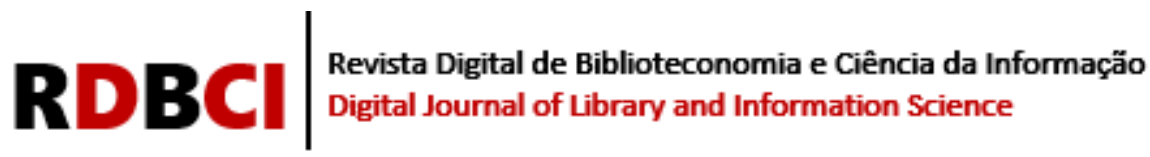

SÁ, Elizabet Dias; CAMPOS, Izilda Maria de; SILVA, Myriam Beatriz Campolina. Inclusão escolar de alunos cegos e com baixa visão. In: ATENDIMENTO EDUCACIONAL ESPECIALIZADO EM DEFICIÊNCIA VISUAL, 2007, Brasília, DF.

SANTANA, Vinícius da Silva de. MP Debate: análise e revisão crítica de um produto audiovisual educacional da Escola Superior do MPPR. 2019. 30 p. Monografia (Especialização em Inovação e Tecnologias na Educação) - Universidade Tecnológica Federal do Paraná. Curitiba, PR, 2019.

SANTOS, Aline Darc Piculo dos et al. Tecnologia Assistiva para Pessoas com deficiência visual: uma análise da produção tecnológica no Brasil. Cadernos de Prospecção, Salvador, BA, v. 11, n. 5, ed. esp., dez. 2018.

SARACEVIC, Tefko. Interdisciplinary nature of information science. Ciência da Informação, Brasília, v. 24, n. 1, 1995.

SARACEVIC, Tefko. Ciência da informação: origem, evolução e relações. Perspectivas em Ciência da Informação, Belo Horizonte, v. 1, n. 1, pag. 41-62, jan / jun. 1996.

SASSAKI, Romeu Kazumi. Nada sobre nós, sem nós: Da integração à inclusão - Parte 2. Revista Nacional de Reabilitação, ano 10, n. 58, p.20-30, set./out. 2007.

SENS, André Luiz; PEREIRA, Alice Therezinha Cybis. Reflexões sobre o design de jogos digitais acessíveis: casos de Papa Sangree e BlindSide. In: CONGRESSO NACIONAL DE AMBIENTES HIPERMÍDIA PARA APRENDIZAGEM, 2015, São Luis, MA. Disponível em: http://conahpa.sites.ufsc.br/wp-content/uploads/2015/06/ID37_Sens-Pereira.pdf Acesso em 18 jun. 2017

SILVA, Wesley Pereira da. Jogos digitais adaptados para estudantes com deficiência visual: estudo das habilidades cognitivas no Dosvox. 2017. Dissertação (Mestrado em Educação) - Universidade de Brasília. Brasília, DF, 2017.

SILVA JÚNIOR, Elias dos Santos. A internet das coisas e a plataforma Arduíno como computação embarcada em mapas táteis: uma avaliação dessa tecnologia assistiva para o ensino das pessoas ouvintes com deficiência visual. 2018. Dissertação (Mestrado Profissional em Diversidade e Inclusão) - Instituto de Biologia, Universidade Federal Fluminense, Rio de Janeiro, RJ, 2018.

VEJA SAÚDE. OMS decreta pandemia do novo coronavírus. Saiba o que isso significa. 11 Mar. 2020. Disponível em: https://saude.abril.com.br/medicina/oms-decreta-pandemia-donovo-coronavirus-saiba-o-que-isso-significa/ Acesso em 23 Jun. 2020 


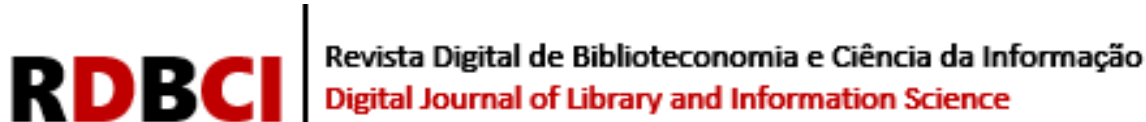

